\title{
Economic Evaluation pf Antibacterial Usage in Ear, Nose and Throat Infections in a Nigerian Teaching Hospital
}

\section{Abstract}

Purpose: To carry out economic evaluation of antibacterial usage for Ear, Nose and Throat infections in a tertiary health care facility in Nigeria.

Methods: Antibacterial utilisation evaluation was carried out retrospectively over one year period by reviewing 122 case notes containing 182 prescriptions of patient with Ear Nose and Throat infections. Relevant data including demographics, diagnosis, prescribed drugs, dosages, were extracted and the associated costs analysed.

Results: Highest prevalent rate of Ear, Nose and Throat infections occurred in children under 10 years of age $(59.3 \%)$ with otitis media predominating $(45.0 \%)$. Average antibacterial cost per case was \$1971.37 (US\$15.16). Penicillins were the most frequently prescribed (35.5\%) at a cost of $\$ 89,468.00$ (US\$688.22) representing $24.9 \%$ of the total antibacterial cost. Cephalosporins were used at a rate of $12.1 \%$ with a percentage total antibacterial cost of $48.4 \%$ ( $\$ 173,554.00$, US\$1335.03).

Conclusion: The average cost of antibacterial agents to patients studied is high. This call for prudent use of these agents which should be evidence based and closely monitored.

Keywords: Pharmacoeconomics, Antibacterial Therapy, Antibacterial Utilization Studies, Infectious diseases.

\author{
Ismail A Suleiman ${ }^{1} *$ \\ Fola Tayo ${ }^{2}$ \\ Department of Clinical Pharmacy \\ and Biopharmacy, Faculty of \\ Pharmacy, College of Medicine \\ Campus, Idi-Araba, PMB 12003 \\ Surulere, Lagos, Nigeria
}

*For correspondence:

Now at Department of Clinical Pharmacy and Pharmacy Practice, Niger Delta University, Wilberforce Island, PMB 071, Yenagoa Bayelsa State, Nigeria

Tel: $+234-8023433337$

Email: suleimanismail@yahoo.com

This article is available in Embase, Index Corpenicus, Scopus, PubsHub, Chemical Abstracts, Socolar, EBSCO, African Journal Online, African Index Medicus, Open-J-Gate, Directory of Open Access Journals (DOAJ) databases

\section{Introduction}

Drug utilization review is one of the conceptual models for effective use of drugs [1], particularly if cost evaluation is included. In most developing countries, regulatory capacity is very weak, most laboratories are poorly equipped and researches are poorly funded. Institutionally organized drug utilization evaluation does not exist in most hospitals as well. In most of these countries, important data on antibacterial usage for sound policy and formidable decisions remain scarce. 
"Community-acquired respiratory tract infections (RTIs) including bacterial sinusitis, acute otitis media, acute exacerbations of chronic bronchitis and community acquired pneumonia (CAP) are among the most frequent infections treated by physicians and represent a major international health problem" [2]. It has been reported that about $10 \%$ of the worldwide burden of morbidity and mortality relates to RTIs [3]. Whilst the majority of this is viral in aetiology, three quarter of all antibiotic consumption is for RTIs [3]. Ongoing threat of antibacterial resistance coupled with irrational use by the public and some health care professionals and poor surveillance activities in most developing countries are indeed compelling reasons for concern.

Infectious diseases have the greatest impact on human being because of their externality. Non affordability of quality therapy by infected patients has serious implications on the health and wealth of the nation. Delay or non-treatment leads to complications, increase cost, increase morbidity and mortality and spread due to communicable nature. Inadequate or inappropriate treatment equally leads to development of resistance in addition. World Health Organization (WHO) in 2006 also pointed out that one-third of the global population has no access to good quality Medicines [5]. Therefore, any useful intervention that can encourage accessibility and affordability will go along way particularly in poor countries like Sub-Sahara Africa where dropping out of therapy due to cost has been reported [4].

In today's competitive, limited-resource healthcare environment, choices and trade offs in providing healthcare services are inevitable. In developing countries, the cost of healthcare is prohibitive and borne mostly from out of pocket expenses. Economic evaluation is increasingly being advocated even in developed countries $[6,7]$, but this is inadequately so in Nigeria among other African countries where available resources for healthcare are much more limited. Previously, emphasis has been basically on clinical outcomes of therapy with little critical consideration for economic and psychosocial outcomes [8,9]. Evidence-based cost related studies are very rare in Nigeria and among other developing countries for accurate health budget planning and reliable policy making the studies imperative. The objective of the study was to carry out economic evaluation of antibacterial usage for Ear, Nose and Throat infections in the chosen tertiary health care facility.

\section{Methods}

\section{Setting}

The study was carried out in the 764-bed Lagos University Teaching Hospital (LUTH), Nigeria which is a tertiary health care centre. The hospital comprises Accident and Emergency Unit as well as In-patient and General Out-Patient units including Ear, Nose and Throat (ENT) clinic. Total patient turnover in the hospital is about 10,000 monthly. Various specialties and wards as well as diagnostic facilities, typical of teaching hospitals, are in place. Antibacterial agents, if indicated, are prescribed in all the departments for surgical and medical cases. The personnel involved are as typical of any teaching hospital comprising the consultants, resident doctors, pharmacists, medical laboratory scientists among others. Each of the hospital department has a pharmacy unit attached.

\section{Study design}

This was a retrospective drug utilization evaluation involving the use of randomly selected 525 out-patient case notes for three categories of disease conditions that has antibacterial agents as the mainstay of therapy. This sample exceeded the calculated 384 case notes using standard statistical procedure. The period covered the year 2005 to 2006 . Out of the randomly selected case notes, the entire 122 containing 182 prescriptions for Ear, Nose and Throat Infections were examined. The systematic randomised sampling was facilitated with the aid of diagnostic coding cards. All age groups of relevant out-patients with antibiotic prescription(s) were included in the study. 


\section{Data collection}

Relevant data such as date of visit, demographics, diagnosis, type of diagnostic test, prescribed drugs, and dosages, frequency of dosing and duration of therapy were extracted using an appropriately designed and validated data collection forms. Follow-up visit if any, and test of cure (a repeat diagnostic test within a month of therapy to ascertain complete eradication of infection or otherwise) were also collected.

\section{Outcome measures}

The surrogate clinical outcome measure determined included hospital visits, type of diagnostic tests and respective proportion of patients involved, test of cure and isolated organisms. Others were volume (in doses), type and class of antibacterial agents prescribed and appropria-teness. Also considered was whether the prescription was in generic or branded names. Economic outcomes included the cost per defined daily dosage of each agents (C/DDD) [10], antibacterial cost per visit for each patient and cost of each class of antibacterial agent. Others were average cost per dose of antibacterial agent, average cost of antibacterial agents per patient. There was no adjustment for discounting and inflation in cost determination as all the costs occurred within one year of data collection. However, the exchange rate of the local currency (naira, to the US dollar (US\$) at the time of analysis was used to allow for consistency.

\section{Data Analysis}

The collected data were analysed using Epi Info (CDC, 2002). Mean cost per defined daily dose (C/DDD) and the total cost of antibacterial agents per visit for each patient were computed for each drugs. Defined daily dose has been recommended for cost analysis of drugs [10]. Also determined were the proportions of prescriptions in generic and branded names, the cost for each class of antibacterial agents, and number of visits. The volume of usage in doses for each drug and respective class of antibacterial agents were also computed. Proportional data were analysed using chi square test and Fisher's exact test (for small numbers) while mean costs were compared using Student $\mathrm{T}$ test. Descriptive statistics (means and percentages) were used in the presentation of results. At $95 \%$ confidence interval, a 2-tailed pvalue less than 0.05 was considered significant.

\section{Results}

\section{Demographic Data and Hospital Visit}

Disease occurrence was significantly higher among children of age group 0-10 years (59.3\%) when compared to any other age group $(\mathrm{p}<0.05)$. There was no significant difference between male $(57.7 \%)$ and female $(42.3 \%)$ patients $(\mathrm{p}<0.05)$ Follow-up visits to the hospital by patients $(33.0 \%)$ was significantly lower than first visits $(67.0 \%)$ by patients $(\mathrm{p}<0.05)$ (Tables 1 and 2$)$.

Table 1: Demographic data and hospital visit among ENTI patients

\begin{tabular}{|c|c|c|c|c|c|}
\hline \multirow{2}{*}{$\begin{array}{c}\text { Age } \\
\text { (Years) }\end{array}$} & \multicolumn{2}{|c|}{ Sex } & \multicolumn{2}{|c|}{ Visit } & \multirow{2}{*}{$\begin{array}{c}\text { Total } \\
\mathrm{N}(\%)\end{array}$} \\
\hline & $\begin{array}{c}\text { Male } \\
\mathrm{N}(\%)\end{array}$ & $\begin{array}{c}\text { Female } \\
\mathrm{N}(\%)\end{array}$ & $\begin{array}{c}\text { First } \\
\mathrm{N}(\%)\end{array}$ & $\begin{array}{c}\text { Follow-up } \\
\mathrm{N}(\%)\end{array}$ & \\
\hline $0-10$ & $66(36.2)$ & $42(23.1)$ & $65(35.7)$ & $43(23.6)$ & $108(59.3)$ \\
\hline $11-20$ & $4(2.2)$ & $5(2.8)$ & $8(4.4)$ & $1(0.5)$ & $9(4.9)$ \\
\hline $21-30$ & $9(4.9)$ & $13(7.1)$ & $20(10.9)$ & $2(1.1)$ & $22(12.1)$ \\
\hline $31-40$ & $15(8.2)$ & $5(2.8)$ & $18(9.9)$ & $2(1.1)$ & $20(10.9)$ \\
\hline $41-50$ & $2(1.1)$ & $3(1.6)$ & $5(2.7)$ & $0(0.0)$ & $5(2.7)$ \\
\hline $51-60$ & 3 (1.6) & $9(4.9)$ & $4(2.2)$ & $8(4.4)$ & $12(6.6)$ \\
\hline$>60$ & $6(3.3)$ & $0(0.0)$ & $2(1.1)$ & $4(2.2)$ & $6(3.3)$ \\
\hline Total & $105(57.7)$ & $77(42.3)$ & $122(67.0)$ & $60(33.0)$ & $182(100.0)$ \\
\hline
\end{tabular}

ENTIs $=$ Ear, Nose and Throat Infections

Int J Health Res, March 2011; 4(1): 47 
Table 2: Age group and prevalent ear, nose and throat infections

\begin{tabular}{ccccccc}
\hline Age & AOM & CSOM & B/Pneumonia & Tonsilitis & Others & Total \\
$($ Years $)$ & $\mathrm{N}(\%)$ & $\mathrm{N}(\%)$ & $\mathrm{N}(\%)$ & $\mathrm{N}(\%)$ & $\mathrm{N}(\%)$ & $\mathrm{N}(\%)$ \\
$0-10$ & $22(12.1)$ & $15(8.2)$ & $65(35.7)$ & $3(1.6)$ & $3(1.6)$ & $108(59.3)$ \\
$11-20$ & $5(2.8)$ & $2(1.1)$ & $1(0.5)$ & $0(0.0)$ & $1(0.5)$ & $9(5.0)$ \\
$21-30$ & $8(4.4)$ & $4(2.2)$ & $0(0.0)$ & $6(3.3)$ & $4(2.2)$ & $22(12.1)$ \\
$31-40$ & $3(1.6)$ & $6(3.3)$ & $0(0.0)$ & $3(1.6)$ & $8(4.4)$ & $20(10.9)$ \\
$41-50$ & $1(0.5)$ & $1(0.5)$ & $1(0.5)$ & $0(0.0)$ & $2(1.1)$ & $5(2.7)$ \\
$51-60$ & $1(0.5)$ & $9(5.0)$ & $2(1.1)$ & $0(0.0)$ & $0(0.0)$ & $12(6.6)$ \\
$>60$ & $5(2.7)$ & $0(0.0)$ & $1(0.5)$ & $0(0.0)$ & $0(0.0)$ & $6(3.3)$ \\
Total & $45(24.7)$ & $37(20.3)$ & $70(38.5)$ & $12(6.6)$ & $18(9.9)$ & $182(100.0)$ \\
\hline \multicolumn{5}{c}{ AOM $=$ Acute Otitis Media, CSOM= Chronoc Suppurative Otitis Media, B= Bronchopneumonia }
\end{tabular}

\section{Clinical variables}

Otitis media was the most prevalent and occurred among $82(45.0 \%)$ patients. Acute and chronic suppurative otitis media occurred in $45(24.7 \%)$ and $37(20.3 \%)$ of the patients respectively. This was followed by bronchopneumonia which occurred among $70(38.5 \%)$ patients. Treatments were largely empirical and there were documented cases of microscopy culture and sensitivity $(\mathrm{m} / \mathrm{c} / \mathrm{s})$ test in $14(7.7 \%)$ patients.

\section{Drug indicator variables}

The total number of drugs prescribed in generic names were $95(34.1 \%)$ which is significantly lower than those prescribed in brand names 180 $(65.9 \%)(\mathrm{p}<0.05)$. Average number of drugs per prescription was 1.5 and the volume of antibacterial agent prescribed in doses was 5571 doses. Penicillins, the most frequently prescribed shares $35.5 \%$ of the total prescriptions (Table 3 ).

\section{Cost variables}

The total antibacterial cost was $\$ 358,760.00$ (US\$2759.92) with an average cost per case of \$1971.37 (US\$15.16) and average cost per dose of \$64.40 (US\$0.49). Penicillins shares $\$ 89,468.00$ (US $\$ 688.22$ ) representing $24.9 \%$ of the total antibacterial cost. Cephalosporins which were prescribed in $12.1 \%$ of the cases had the largest antibacterial share cost of $\$ 173,554.00$ (US\$1335.03), with a cost proportion of $48.4 \%$. Average antibacterial cost for otitis media was N825.00(US\$6.35) while that of bronchopneumonia was $\$ 3675.41 \pm 1207.58$ (US\$28.27 \pm 9.28 ) (Table 4).
Table 3: Volume of usage of antibacterial agent in treatment of ENTIs

\begin{tabular}{llll}
\hline & $\begin{array}{l}\text { Frequency } \\
\text { as First }\end{array}$ & $\begin{array}{l}\text { Frequency Volume } \\
\text { as Follow- of Usage }\end{array}$ \\
& $\begin{array}{l}\text { Choice } \\
\text { Drug choice }\end{array}$ & $\begin{array}{l}\text { up chass } \\
\mathrm{N}(\%)\end{array}$ & Doses (\%) \\
\hline Penicillins & $73(26.7)$ & $24(8.8)$ & $2416(43.4)$ \\
Cephalosporins & $13(4.8)$ & $20(7.3)$ & $430(7.7)$ \\
Macrolides & $16(5.9)$ & $12(4.4)$ & $692(12.4)$ \\
Quinolones & $7(2.6)$ & $5(1.8)$ & $150(2.7)$ \\
Aminoglycosides & $8(2.9)$ & $7(2.6)$ & $207(3.7)$ \\
Sulphonamides & $5(1.8)$ & $6(2.2)$ & $128(2.3)$ \\
Imidazoles & $20(7.3)$ & $13(4.8)$ & $693(12.4)$ \\
Others & $30(10.9)$ & $14(5.1)$ & $855(15.3)$ \\
Total & $172(63.1)$ & $101(36.9)$ & $5571(100.0)$ \\
\hline
\end{tabular}

ENTIs = Ear. Nose and Throat Infections

\section{Discussion}

Otitis media which was the most prevalent in almost half of the patient, has been previously reported as the commonest Ear, Nose and Throat infection with a prevalence rate of $14.7 \%$ in children 0-12 years and $29.0 \%$ in children 0-5 years of age in South-Western Nigeria [11]. With a population of about 140 million [12], 29.0\% in children below 5 years (who normally constitute $20.0 \%$ of total population) implies about 7.7 million cases in Nigeria. Majority of the affected children usually belong to low socio economic group who can hardly afford basic health care as a result of an association between infections, poor sanitary conditions and low standard of living. Most Nigerians (70.2\%) have been reported to be living below the poverty line earning less than US\$1 per day even before global economic

Int J Health Res, March 2011; 4(1): 48 
Table 4: Antibacterial utilization in the treatment of Ear, Nose and Throat infections

\begin{tabular}{|c|c|c|c|c|}
\hline Drug Class & Drug & $\begin{array}{l}\text { Prescription } \\
\text { Frequency } \\
\text { N }(\%)\end{array}$ & 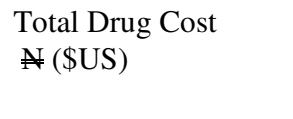 & $\begin{array}{l}\text { Percentage Drug Cost } \\
(\%)\end{array}$ \\
\hline \multirow[t]{3}{*}{ Quinolones } & Ciprofloxacin & $8(2.9)$ & $4,468.00(34.40)$ & 1.2 \\
\hline & Others & $4(1.5)$ & $12,498.00(96.14)$ & 3.4 \\
\hline & Sub Total & $12(4.4)$ & $16,888.00(129.90)$ & 4.6 \\
\hline \multirow[t]{6}{*}{ Penicillins } & Cloxacillin & $2(0.7)$ & $900.00(6.92)$ & 0.3 \\
\hline & Coamoxiclav & $33(12.1)$ & $61,096.00(469.97)$ & 17.0 \\
\hline & Amoxicillin & $32(11.7)$ & $9,278.00(71.37)$ & 2.6 \\
\hline & Ampicillin & $7(2.6)$ & $2,464.00(18.95)$ & 0.7 \\
\hline & Ampiclox & $23(8.4)$ & $15,730.00(121.00)$ & 4.4 \\
\hline & Sub-Total & $97(35.5)$ & $89,468.00(688.20)$ & 24.9 \\
\hline \multirow[t]{4}{*}{ Cephalosporins } & Ceftriaxone & $2(0.7)$ & $12,864.00(989.72)$ & 24.9 \\
\hline & Cefuroxime & $28(10.3)$ & $59,820.00(460.15)$ & 16.7 \\
\hline & Ceftazidime & $3(1.1)$ & $100,870.00(775.92)$ & 28.1 \\
\hline & Sub Total & $33(12.1)$ & $173,554(1335.03)$ & 48.4 \\
\hline \multirow[t]{3}{*}{ Macrolides } & Erythromycin & $27(9.9)$ & $10,852.00(83.47)$ & 3.0 \\
\hline & Roxiithromycin & $1(0.4)$ & $650.00(5.0)$ & 0.2 \\
\hline & Sub Total & $28(10.3)$ & $11,502.00(88.48)$ & 3.0 \\
\hline \multirow[t]{3}{*}{ Aminoglycosides } & Gentamicin & $14(5.1)$ & $5,240.00(40.31)$ & 1.4 \\
\hline & Amikacin & $1(0.4)$ & $43,820.00(337.08)$ & 12.2 \\
\hline & Sub-Total & $15(5.5)$ & $49,060.00(377.38)$ & 13.7 \\
\hline Sulphonamides & Co-trimoxazole & $11(4.0)$ & $2,152.00(16.55)$ & 0.6 \\
\hline Imidazoles & Metronidazole & $33(12.1)$ & $3,636.00(27.97)$ & 1.0 \\
\hline \multirow{2}{*}{ Others } & Ear Drops & $44(16.1)$ & $12,530.00(96.38)$ & 3.5 \\
\hline & Grand Total & $273(100.0)$ & $358,790.00(2759.92)$ & 100.0 \\
\hline
\end{tabular}

Exchange rate at the time of the study: $\$ 1=130 ;$ No adjustment for inflation or discounting was carried out

meltdown ${ }^{12}$ indicating poor affordability of quality health care services.

Average antibacterial cost from the study for treating otitis media was $\$ 825.00$ (US\$6.35) $\{$ \$542 \pm 62.00 SEM (US $\$ 4.17 \pm 0.48$ ) for acute and $\$ 1161.68 \pm 221.4$ SEM (US\$8.93 \pm 1.7 ) for chronic suppurative\}. This gives about $\$ 6.35$ billion (US\$48.87 million) as antibacterial cost alone for an estimated 7.7 million cases of otitis media in Nigeria. Average antibacterial cost of $\$ 3675.41 \pm 1207.58$ (US\$28.27 \pm 9.28 ) for bronchopneumonia is also prohibitive. Overall average antibacterial cost per case of \$1971.37 (US\$15.16) is very high. Poor patients can hardly afford this, complications and spread of the infections occurs particularly in crowded settings of low socio economic group. Free health care from government is strongly advocated for children below 12 years. Education of patients and care givers on personal hygiene, environmental sanitation is also necessary. There should be enhanced capacity building and facility provision to promote rapid diagnosis. Provision of regularly up-dated evidence-based treatment guidelines, data base on antibacterial resistance and sustainable surveillance activities, to guide empiric therapy are also necessary.

The antibacterial agents were rationally prescribed but largely empirical. Antibacterial susceptibility testing in seven percent of cases reviewed is very low. Empirical antibacterial therapy is a major factor in the development of antibacterial resistance $[13,14]$. However, empiric therapy is somewhat inevitable in Nigeria due to poor diagnostic facilities and poverty among many patients who may not be able to afford quality health care services. Over the counter prescription of antibacterial agents even by quacks, in effective drug distribution system, weak regulations and poor surveillance activities are other factors seriously threatening antibacterial therapy success in Nigeria and other 
developing countries. It is important to address these by all the stakeholders urgently.

More than two-third of prescriptions were in branded names instead of generic $(p<0.05)$ in contrary to recommendations of National Drug Policy of 2005[15]. Lack of adequate awareness on the implications may be responsible. It makes patients to think that generic products are inferior; hence societies including poor teaming masses are tactically being forced to spend more in buying the branded products. However, lack of trust as regard the quality of some generic products might be a factor. Generic prescription should be encouraged particularly for developing countries where health spending per capita is about US\$15.00 - US\$21.00 annually, unlike developed countries where per capita health spending is about US\$2000.00[16]. Quality control of generics should be strengthened and evidence of efficacy ascertained periodically.

The most widely prescribed class of drug was the penicillins at a frequency of $35 \%$, at a cost of $\$ 89,468.00$ (US\$688.22) representing $24.9 \%$ of total antibacterial cost for all agents. This observation is in agreement with previous reports [17]. Cephalosporins were second to the penicillins at a prescribing rate of $12.1 \%$ but with a whopping cost of $\$ 173,554$ (US\$1335.03) which represents about half of the total antibacterial cost. Out of the $12.1 \%$, cefuroxime alone constitutes $10.1 \%$ but only $16.7 \%$ of the huge cost. This is probably because of its availability in oral formulations in addition to injection.

The cost proportions of co-amoxiclav among the penicillins and other cephlosporins apart from cefuroxime indicates that usually few drugs are responsible for high total cost of antibacterial therapy. Their usage should be monitored and cost effectiveness analysis carried out on regular basis to monitor their use and optimise therapy.

\section{Conclusion}

Antibacterial cost to patients and by extension the nation at large is enormous and a greater proportion of the antibacterial cost is due to few agents. This call for prudent use of these agents which should be evidence based and closely monitored.

\section{Acknowledgment}

The cooperation of the hospital management, physicians, pharmacist, and medical record officers is well appreciated.

\section{Conflict of Interest}

No conflict of interest associated with this work.

\section{Contribution of authors}

We declare that this work was done by the author(s) named in this article and all liabilities pertaining to claims relating to the content of this article will be borne by the authors. IAS contributed to the concept and design of the work, conducted a literature search, collected and analysed the data, and prepared the manuscript. FT contributed to the concept and design, contributed important intellectual content and edited the manuscript.

\section{References}

1. World Health Organisation. WHO Global Strategy for the containment of antimicrobial resistance. Geneva: The Organisation 2001.

2. World Health Organization. Report of infectious diseases; 2000, WHO/CDS/2000.2

3. Anonymous. Acute respiratory infections: the forgotten pandemic. Communiqué from the International Conference on Acute respiratory Infections, Canberra, Australia 7-10 July 1997. Int J Tuberc Lung Dis 1998;2:675

4. La-Ruche G, Lorougnon F and Digbeu N. Therapeutic algorithms for the management of sexually transmitted diseases at the peripheral level in Cote'd Ivoire: assessment of efficacy and cost. Bulletin of the World Health organisation 1995; 73:305-13

5. World Health organisation. Medicine Prices Surveys and Proposed Interventions to improved sustainable access to affordable medicines, in six Sub-Sahara African Countries Geneva: World Health Organisation; 2006

6. Florence R. An Introduction to Health Economics. Pharm J 2003; 271: 679-681.

7. Malek M. Decision Analysis and Quality Control. Pharm J 1997;258:99-01

Int J Health Res, March 2011; 4(1): 50 
8. Townsend $\mathrm{R} H$. Postmarketing drug research and development. Drug Intelligence and Clin Pharm 1987; 21:134-136

9. Drummond MF, Smith GT, and Wells N. Economic Evaluation in the development of medicines. London. The Office of Health Economics. 1988.

10. Nertheimer, AI. The defined daily dose system(DDD) for drug utilisation review Hosp Pharm; 1986; 21:233-41.

11. Amusa YB, Ijadunola IK and Onajade $\mathrm{OO}$ Epidemiology of otitis media in a local tropical African population; West Afr J of Med; 2005; 24(3);227-30.

12. United Nations Development Prigramme (UNDP) Technical Report On Nigeria, 2004.

13. Ball P. Baquero F, Cars O. Antibiotic therapy of community respiratory tract infections: strategies for optimal outcomes and minimized resistance emergence. J. Antimicrob Chemother 2002;49:3140.

14. Okeke IN, Lamikanra A, and Edelman $\mathrm{R}$ Socioeconomic and Behavioural factors Leading to Acquired Bacterial Resistance to Antibiotics in Developing Countries. Emerg Infect Dis; 1999; 5(1):1-14.

15. National Drug Policy. Federal Ministry of Health Abuja, Nigeria. 2005

16. The Guardian (London). Health spending per capita. The Guardian (London). 2005;25:03:05

17. American Thoraxic Society. Guidelines for the Management of Adults with Community-acquired Pneumonia. Am. J. Respir Crit Care Med 2001; 163:1730-1754.

Int J Health Res, March 2011; 4(1): 51 
Int J Health Res, March 2011; 4(1): 52 